\title{
Australian Rangelands as Complex Adaptive Systems: A Conceptual Model and Preliminary Results
}

\author{
J.E. Gross ${ }^{\mathrm{a}}, \underline{\text { R. McAllister }}{ }^{\mathrm{a}}$, N. Abel ${ }^{\mathrm{b}}$, D.M. Stafford-Smith ${ }^{\mathrm{c}}$, and Y. Maru ${ }^{\mathrm{c}}$ \\ ${ }^{a}$ CSIRO Sustainable Ecosystems, Davies Laboratory, Aitkenvale, Queensland, Australia \\ ${ }^{\mathrm{b}}$ CSIRO Sustainable Ecosystems, Gungahlin, Canberra, Australia \\ ${ }^{\mathrm{c} C S I R O}$ Center for Arid Zone Research, Alice Springs, Northern Territory, Australia
}

\begin{abstract}
Models that seek to guide decisions on policy in rangelands must address the close links between ecological, economic, and social processes, and the adaptation of participants through time. We used an agent-based modeling approach to implement a parsimonious conceptual model of rangelands that includes biophysical processes central to the functioning of rangelands, commercial enterprises, and institutions. The model operates on a monthly time step, and uses economic and biophysical conditions to stimulate changes in management policies and learning. Our simple model reproduces the general patterns of forage growth and livestock dynamics, and results illustrate consequences of interactions between environmental heterogeneity and learning rate.
\end{abstract}

Keywords: Rangelands; Complex adaptive system; Social-ecological system; Savanna

\section{INTRODUCTION}

Rangelands occupy many semi-arid parts of the world where precipitation is sufficient to support growth of forage but insufficient to regularly produce cultivated crops. Because production is strongly driven by precipitation, which is often erratic and variable, production of forage is also highly variable between years and these systems may be far from an equilibrium for much of the time. The concepts of non-equilibrial systems and non-equilibrial dynamics are well established in ecology (deAngelis and Waterhouse, 1987) and they now form the foundation for a dominant view of semi-arid rangeland dynamics (Ellis and Swift, 1988; Behnke and Scoones, 1992). Due to the absence of a consistent "stable state" in rangelands, complex plant-herbivore dynamics can result solely from variation in the primary biophysical drivers. However, additional complexity in rangeland vegetation dynamics arises from the existence of thresholds, where non-linear responses of vegetation to grazing and other environmental drivers leads to changes that are effectively one-way and that cannot be reversed on a reasonable time scale without substantial intervention (Hollings, 1973; Friedel, 1991; Laycock, 1991). High variation in precipitation, non-equilibrial dynamics, and thresholds are all characteristics of rangelands that challenge our ability to model and predict rangeland dynamics.

Here, we focus on rangelands in NE Australia, where humans make key decisions on stocking rates, animal movements, and other actions that influence livestock and land condition. These rangelands are closely linked social-ecological systems where livestock management can have a dominating effect on vegetation and other landscape attributes. Management of rangelands is thereby further complicated by the need to simultaneously consider biophysical and social dynamics. Decisions (e.g., stocking rate) based on economic or other livelihood criteria may be driven by global markets, national policy, regional trends, or other factors outside direct control of the producer. Again, these factors contribute to uncertainty in predicting system dynamics and in making decisions on rangeland management.

Given the difficulties in accurately predicting either the biophysical or social dynamics of rangelands, it is not surprising that management of rangelands has been contentious. There have been intense debates on the sustainability of grazing practices in the more developed countries, while expensive and prolonged attempts to improve rangeland management in developing countries have been criticized for having had very limited success (Behnke and Scoones, 1992).

Recognition of the inherent uncertainty and nonlinear responses of ecosystems to human intervention has caused a shift from management based on "command and control" (Holling and Meffe, 1996) to one that values diversity over homogeneity and that strives for resilience over stability (Folke et al., 2002; Walker and Abel, 
2002). Rangelands are social-ecological systems experiencing constant change, where resilience is central to enhancing adaptive capacity.

Appropriate institutional arrangements appear to be a key component of resilient systems. Flexible social networks and institutions at multiple levels, from local to national, with overlapping authority and capabilities, have been promoted as a means for enhancing resilience and adaptive capacity (McGinnis, 2000). Managers and policy-makers attempting to increase resilience of rangelands are thus confronted with a bewildering range of biophysical, social, and economic considerations.

Rangelands are complex adaptive systems and new conceptual and quantitative models are needed to support management of rangelands at local, regional, and national scales. Both the biophysical and human-dominated components of rangeland systems respond and adapt to system states, thus the processes of evolution and learning are critical in rangeland systems. Such an adaptive system can be evaluated within the framework defined by the emerging science of complex systems, and the application of complex system science methods may provide new insights to rangeland dynamics. In particular, agent-based models and computer-assisted reasoning provide new potential for gaining new insights to systems where decisions are based on criteria with widely differing currencies, and where a multitude of individual decisions leads to emergent properties at a higher level (Levin, 1998; Lempert, 2002).

\section{APPROACH}

Our goal is to improve our understanding of rangeland dynamics by applying complex systems science methods to the analysis of linked socialecological systems. We focus on dynamics over a period of a decade or a few decades, and on groups of enterprises that are exposed to similar sets of drivers. This paper describes our progress through the development of a conceptual model and implementation of subsystem models.

Many definitions of complex systems exist, but virtually all include several characteristics. We concur with Levin's (1998) evaluation that complex adaptive systems can be identified by three traits: sustained diversity and individuality of components, localized interactions among those components, and an autonomous process that selects a subset of components for replication, based on localized interactions. Most definitions of complex adaptive systems include emergent properties, self-organization, and nonlinearity. These properties will result from continual adaptation ("learning"), the absence of a global controller (important dynamics at local scales), and constant adaptation. Constant adaptation implies continuous change, thus dynamics are typically far from equilibrium where non-linear dynamics are frequently exhibited. The high potential for emergent properties in complex systems arises from interactions of many independent units at local scales. Complex systems are often selforganizing, thus complex higher-level patterns can emerge from the behavior of independent units that follow simple behavioral rules.

The objectives of our modeling experiments are to evaluate general behaviors of rangeland systems (e.g., theoretical studies), and, at case study sites in Australia, to address more specific questions such as:

- Is the institutional structure matched in terms of scale and responsiveness to the ecological and social processes it is intended to influence?

- Are the institutional rules aimed at influencing the appropriate processes (slow or fast, internal or external)?

- Can the institutions cope with lag effects, non-linearities, information gaps and surprises?

- How do institutions conflict or complement each other within and across scales?

- Can the institutions adapt their rules as the social-ecological system evolves?

- What institutional arrangements best foster learning and adaptive capacity?

To address questions of this sort, we concluded that a "minimal model" must accommodate:

- Observed biophysical dynamics.

- Learning and adaptation by agents representing enterprises and institutions.

- Cross-scale interactions.

- Complex patterns of communication between agents.

- Decisions based on criteria expressed in fundamentally different currencies.

\subsection{Conceptual model and implementation}

There have been few attempts at syntheses such as the one we propose. Our conceptual model is intended to be just complicated enough - and no more (Figure 1). As a result, processes are represented at a high level of abstraction. Agentbased modeling (ABM) offers a technique for simulating dynamics of complex systems composed of many interacting parts, where a relatively simple set of rules defines the behaviors of the individual parts. 
We envision the bounds of the physical system as a landscape. The landscape is composed entirely of enterprises, and each enterprise consists of one or more patches. We are concerned with enterprises that represent commercial pastoral enterprises, but an enterprise could have an alternative goal (as defined by its livelihood function), for example a park or other land use.

In the current model, an enterprise was represented as a commercial grazing property. Properties were physically defined by an area, quality of land in each patch, and the livestock associated with the property. The model was designed for simulating an average grazing enterprise in NE Queensland, Australia, near Charters Towers (20.2S, 146.3E), based on survey data of enterprise size and financial structure (Hinton, 1995). Annual precipitation averaged $650 \mathrm{~mm} / \mathrm{yr}$. Biophysical model parameters were calibrated to measurements from paddocks dominated by black speargrass (Heteropogon contortus).

In the context of complex systems analysis, agents in the model include enterprises, patches, livestock, and the government. Behaviors of the agents are defined by a strategy set, and in the case of the enterprise, these rules evolve through time to represent learning. We intend to expand our representation of institutions, including feedbacks between enterprises, weather, and biophysical conditions. In this case, the institutional strategy set would also vary through time, representing coevolution of institutions and other model agents.

The model operates on a monthly time step, although some processes occur on a seasonal, annual or multi-year schedule.

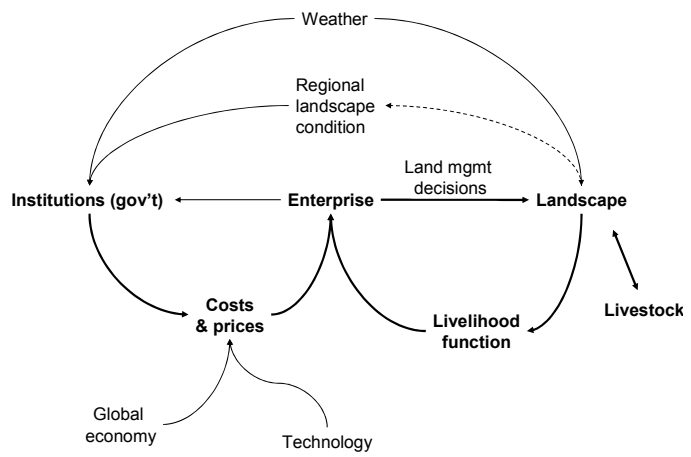

Figure 1. Conceptual diagram of a minimal model for simulating adaptive rangeland systems at the level of groups of enterprises.

\subsection{Biophysical models}

In the current implementation, the main biophysical submodels represent plant and livestock dynamics (Figure 1). In these submodels, the underlying philosophy was to define optimal growth rates, and then reduce these rates by factors that represented the most important constraints and stressors. Weather can constrain plant growth through precipitation or seasonal changes in temperature. Plant growth varied seasonally in a manner consistent with growth of C4 species found in Australia. Multiyear changes in potential plant growth resulted from changes in basal area, which responded on an annual basis to aboveground productivity and to utilization.

Maximum plant production $\left(\mathrm{kg} \mathrm{ha}^{-1} \mathrm{mo}^{-1}\right)$ was a function of basal area, thus the change in green vegetation $(G, \mathrm{~kg} / \mathrm{ha})$ was

$$
d G / d t=B_{a} B_{g \max } M_{\text {precip }} M_{\text {seas }}-S
$$

where $B_{a}$ is basal area (percentage cover), $B_{\text {gmax }}$ is maximum growth per unit of $B_{a}(\mathrm{~kg} / \mathrm{ha}), M_{\text {precip }}$ is a precipitation multiplier (0-1), $M_{\text {seas }}$ is a seasonal growth factor $(0-1)$, and $S$ is senescent rate (proportion).

A key process in rangelands is degradation and the gradual run-down of production. A dynamic basal area function, based on that in the grassland simulation model GRASP (Littleboy and McKeon, 1997), was used to represent the effects of heavy grazing or sustained drought. High rates of utilization or low production (typically the result of drought) led to a reduction in $B_{a}$. There were no restrictions on how rapidly $B_{a}$ could decline, but increases in $B_{a}$ were limited by averaging production over the previous 2 years, and by an absolute factor. Consequently, rates of decline in basal area were typically more rapid than rates of recovery, representing the hysteresis that typically accompanies ecosystem degradation.

Grass growth was partitioned into pools of green and dry material $(\mathrm{kg} / \mathrm{ha})$. These pools varied in nutritional quality and were therefore important to adequately representing livestock dynamics. Parameters in the plant submodel were calibrated to observations of biomass dynamics near Charters Towers, and to outputs from GRASP (Littleboy and McKeon, 1997; parameter set "Burdy11"). The plant submodel we implemented reproduced patterns and quantities of forage that roughly matched observations from the black speargrass paddocks in the Charters Towers region (Figure 2). 
The livestock submodel represented extensively grazed cattle, partitioned into two age classes. It estimated live weight gain (LWG, $\mathrm{kg}$ ) and it included simple diet selection and animal growth functions that interacted with the plant submodel through selection of and consumption of green and dry grass. Growth rates depended on forage availability and quality.

Diet selection is a key process in tropical pastures, and the quality of the diet consumed was determined by the proportion of green forage in the diet. Diet selection was implemented following the basic conceptual model proposed by Blackburn and Kothmann (1991), but in our implementation, selection for green was driven only by the proportion of green in the sward and absolute biomass (Hendricksen et al., 1982; Chacon and Stobbs, 1976). Diet quality was determined from the proportion of the diet composed of grass that grew in the current time step (highest quality green grass), green grass that grew in previous time steps (intermediate quality), and dry grass (lowest quality). Diet selection and diet quality were key drivers of animal growth and condition, which subsequently influenced growth and survival of livestock in the absence of supplemental food.

\subsection{Pastoral Enterprises and learning}

Pastoral enterprise actions were represented by a strategy set which defined management actions and characteristics. This strategy set included criteria for setting a target stocking rate and making other financial decisions (selling cattle, borrowing, etc.). Enterprises accumulated either debt or wealth depending on the overall success of their respective rules through time. Learning is a key characteristic of adaptive systems, and enterprise learning was explicitly represented in the model.

Two financial factors drove evolution of enterprise strategies (i.e. learning). Firstly, for some enterprises the level of financial debt determined whether learning took place. This implies that some model enterprises make strategy changes only when forced to, which is cited as a driving force for innovation in Australian farms (Mortiss, 1995). Secondly, the success of a strategy set (defined by gross margin per ha) determined the chance that the strategy was adopted by other enterprises.

Each enterprise was randomly classified as a fast, medium or non-learner. Each category was associated with a rate of learning, which described the magnitude of a learning event (i.e., a large or small change in behavior). Fast learners incorporated $50 \%$ of the selected strategy set into its new strategy set and did not require financial hardship to motive learning. Medium learners incorporated $25 \%$ of the selected rule, and learning only occurred when debt:capital exceeded $30 \%$. Both slow and fast learners could not experience a learning event more frequently than every 48 months. Non-learners did not learn. Enterprise rules were stored as binary sequences, similar to structures used in genetic algorithms, and a genetic algorithm's approach to "mating" solutions (Holland, 1975) was used to combine an existing rule with a selected rule.

While learning was based on simple rules, many factors contributed to the learning process. Changes in cattle prices and interest rates influenced financial pressure and stimulated learning events. Biophysical properties also influenced rates of learning. For example, in times of drought, decreased productivity could increase financial pressure, particulary in enterprises with strategies poorly equipped to cope with drought (e.g., high stocking rates). Enterprises that face financial difficulty may learn from enterprises with strategies better attuned to current conditions. However, if drought relief was employed by a government to relieve financial pressure, it is possible that poorly adapted enterprises would be less likely to modify their strategies.

The distribution of rules in the system also changed through enterprise failure. If debt:capital of an enterprise was $>60 \%$, the enterprise was deemed to have failed and the strategy set "died". A replacement enterprise was created with a strategy set derived from two strategy sets, which were selected with a probability proportional to the value of their objective function. This process represents a form of system learning and evolution (Janssen et al., 2000).

The model included agents that represented a government and a land broker institution, both of which had fixed rules. The main roles of the government were to collect taxes and deliver drought relief in the form of interest payment subsides. The land broker estimated the value of land contained in an enterprise by discounting its expected future profits (i.e. net present value). The land, being the major capital associated with the enterprise, was used to determine enterprise debt:capital.

\section{RESULTS AND DISCUSSION}

To evaluate model performance for a range of conditions, we conducted simulations of enterprises with a constant heavy ( $0.2 \mathrm{head} / \mathrm{ha})$, moderate $(0.125 \mathrm{hd} / \mathrm{ha})$, or light $(0.08 \mathrm{hd} / \mathrm{ha})$ target stocking rates. The model was driven by 
weather data from 1889 to 2002, and results for a $50-\mathrm{yr}$ period are presented in Figure 2. Results from these simulations confirmed the ability of the model to produce general patterns and trends in stocking rate, live weight gain of cattle, and biomass dynamics that matched observations from the Dalrymple Shire (see Hinton, 1995; Winks et al., 1979). While the overall patterns generally matched observations, there was a notable discrepancy between the rate of

(A)

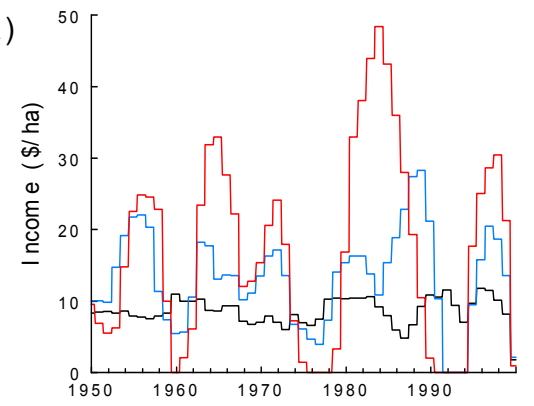

(B)

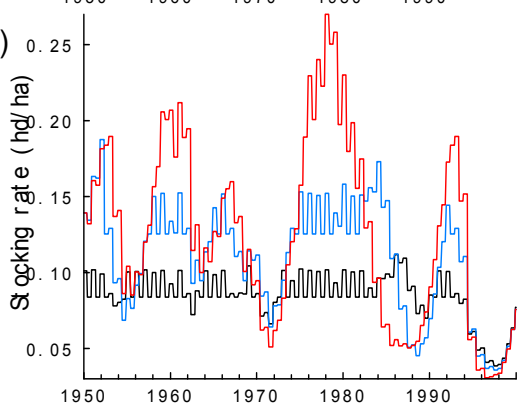

(C)
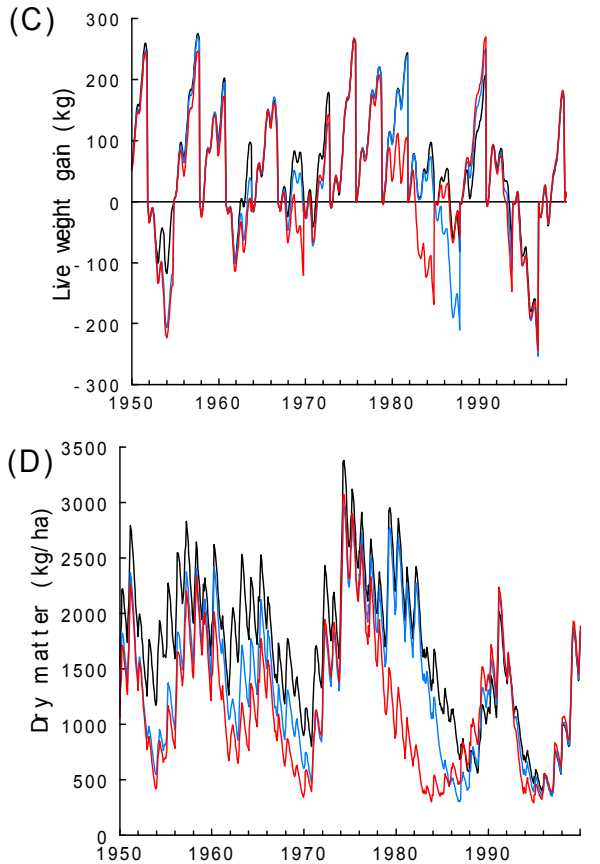

Figure 2. Results of simulations of an examplar enterprise with a constant goal to stock at a high (red), moderate (blue), or low (black) stocking rate. Predictions of (A) income, (B) actual stocking rate, $(\mathrm{C})$ cumulative 3 -yr live weight gain, and (D) standing dry matter. destocking in the model and that observed during droughts in the 1980s and 1990s. The simple and static management strategies employed in these initial simulations resulted in more rapid reductions in stock than those observed.

To investigate effects of learning, we simulated enterprises with fast, slow, or non-learners. Simulations were driven by historical climate, interest rate, and livestock price data from 1895 2000. Each simulation consisted of 300 enterprises and each enterprise was allocated a random stocking rate of 0.500 to 0.055 adult animal equivalents per hectare.

When averaged over the entire simulation period, fast learners obtained the greatest profits (Figure 3). However, no single learning strategy consistently outperformed all others and the fastest learners also experiences the greatest variability in income and associated landscape condition. While fast learners more quickly adapt to rapidly changing environmental conditions, they are exposed to greater risks because they increase stocking rates during periods of high rainfall. They are thereby exposed to high costs of destocking when the rain fails and forage is inadequate to sustain existing stock. In addition to costs associated with inadequate forage, the model includes transaction costs associated with changing strategies.

The results highlight the trade-offs of learning, particularly in systems like semi-arid rangelands that are exposed to highly variable weather patterns or other disturbances. These preliminary results demonstrate the ability of the model structure to incorporate processes that are characteristic of complex adaptive systems, and that are central to determining the dynamics of

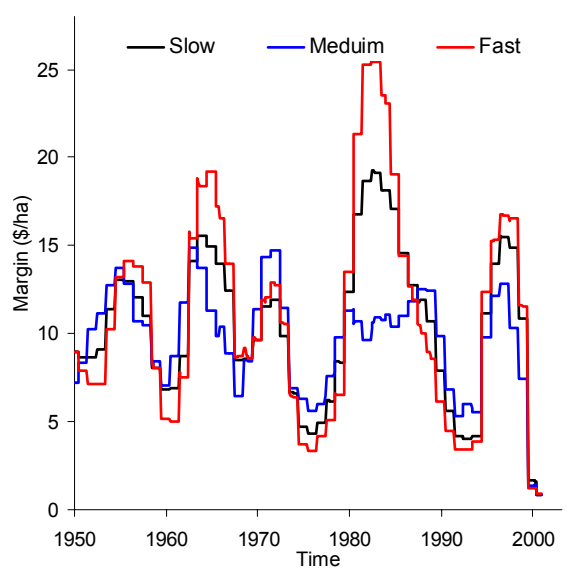

Figure 3. Average gross margin (profit; $\$ /$ ha) fast, slow, and non-learners from 1950-2000. Reduced margins are associated with periods of below average rainfall. 
rangelands. As the model is refined and embellished, we will use it to address questions about relationships between institutions, learning, and ecosystem dynamics. Insights to these processes are essential to developing effective policy on rangeland use, and they can be effectively addressed in the framework of a complex adaptive system. We thank CSIRO's Emerging Science Program in Complex System Science and the Tropical Savannas CRC for supporting this work.

\section{REFERENCES}

Behnke, R.H., and I. Scoones, Rethinking range ecology: implications for rangeland management in Africa. World Bank Environment Working Paper No. 53, 1992.

Blackburn, H.D., and M.M. Kothmann, Modelling diet selection and intake for grazing herbivores, Ecological Modelling 57, 145-163, 1991.

Chacon, E., and T.H. Stobbs, Influence of progressive defoliation of a grass sward on the eating behaviour of cattle, Ausralian Journal of Agricultural Research 27, 709727, 1976.

deAngelis, D.L., and J.C. Waterhouse, Equilibrium and nonequilibrium concepts in ecological models, Ecological Monographs $57,1-21,1987$.

Ellis, J.E., and D.M. Swift, Stability of African pastoral ecosystems: alternate paradigms and implications for development, Journal of Range Management 41, 450-459, 1988.

Folke, C., Carpenter, S., Elmqvist, T., and 22 others. Resilience and sustainable development: Building adaptive capacity in a world of transformations. Background paper, The World Summit on Sustainable Development, for the Environmental Advisory Council to the Swedish Government, 2002.

Friedel, M.H., Range condition assessment and the concept of thresholds: a viewpoint, Journal of Range Management 44, 422-426, 1991.

Hendricksen, R., K.G. Rickert, A.J. Ash, and G.M. McKeon, Beef production model, Animal Production in Australia 14, 204-208, 1982.

Hinton, A.W., Land condition and profit: A study of Dalrymple Shire properties. Queensland Department of Primary Industries, Brisbane, Australia, NLP no. 91/Q/MO4, 41 pages, 1995.

Holland, J.H., Adaptation in natural and artificial systems. University of Michigan Press, Ann Arbor, 1975.

Holling, C.S., Resilience and stability of ecological systems, Annual Review of Ecology and Systematics 4, 1-24, 1973.

Holling, C.S., and G.K. Meffe, Command and control and the pathology of natural resource management, Conservation Biology 10, 328$337,1996$.

Janssen, M.A., B.H. Walker, J. Langridge, and N. Abel, An adaptive agent model for analysing co-evolution of management and policies in a complex rangeland System, Ecological Modelling 131, 249-268, 2000.

Laycock, W.A., Stable states and thresholds of range condition on North American rangelands: a viewpoint, Journal of Range Management 44, 427-433, 1991.

Lempert, R.J., A new decision sciences for complex systems, Proceedings of the National Academy of Sciences of the United States of America 99, 7309-7313, 2002.

Levin, S.A., Ecosystems and the biosphere as complex adaptive systems, Ecosystems 1, 431-436, 1998.

Littleboy, M. and G.M. McKeon, Subroutine GRASP: grass production model. Rural Industries Research and Development Corporation. Final report DAQ-124A, 69 pages, 1997.

McGinnis, M., Polycentric governance and development. University of Michigan Press, Ann Arbor, 2000.

Mortiss, P.D., The environmental issues of the upper Burdekin catchment. Queensland Department of Primary Industries, Brisbane. Project Report QO95017, 76 pages, 1995.

Walker, B.H., and N. Abel, Resilient rangelands adaptation in complex systems, Pages 293313 in: L.H. Gunderson and C.S. Holling, eds. Panarchy: Understanding transformations in human and natural systems. Island Press, Washington, 2002. 